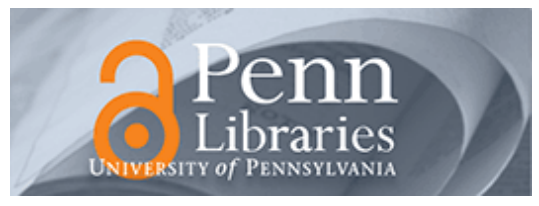

University of Pennsylvania

ScholarlyCommons

Marketing Papers

Wharton Faculty Research

1998

\title{
How Tolerable is Delay? Consumers' Evaluations of Internet Web Sites after Waiting
}

Benedict G.C Dellaert

Barbara E. Kahn

University of Pennsylvania

Follow this and additional works at: https://repository.upenn.edu/marketing_papers

Part of the Behavioral Economics Commons, Business Administration, Management, and Operations Commons, Business Analytics Commons, Business and Corporate Communications Commons, Cognition and Perception Commons, Cognitive Psychology Commons, E-Commerce Commons, Marketing Commons, Sales and Merchandising Commons, and the Technology and Innovation Commons

\section{Recommended Citation}

Dellaert, B. G., \& Kahn, B. E. (1998). How Tolerable is Delay? Consumers' Evaluations of Internet Web Sites after Waiting. Journal of Interactive Marketing, 13 (1), 41-54. http://dx.doi.org/

10.1002/(SICI)1520-6653(199924)13:1<41::AID-DIR4>3.0.CO;2-S

This paper is posted at ScholarlyCommons. https://repository.upenn.edu/marketing_papers/257

For more information, please contact repository@pobox.upenn.edu. 


\title{
How Tolerable is Delay? Consumers' Evaluations of Internet Web Sites after Waiting
}

\author{
Abstract \\ The effect of waiting times on consumers' retrospective evaluations of internet web sites is investigated \\ in four computer-based experiments. Results show that waiting can, but does not always, negatively \\ affect evaluations of web sites. They also show that the potential negative effects of waiting can be \\ neutralized by effectively managing waiting experiences. A conceptual framework and formal random \\ utility model are introduced.

\section{Keywords} \\ marketing, consumer preference models, waiting experiences, Internet marketing

\section{Disciplines} \\ Behavioral Economics | Business | Business Administration, Management, and Operations | Business \\ Analytics | Business and Corporate Communications | Cognition and Perception | Cognitive Psychology | \\ E-Commerce | Marketing | Sales and Merchandising | Technology and Innovation
}




\title{
How Tolerable is Delay? Consumers' Evaluations of Internet Web Sites after Waiting
}

\author{
Benedict G.C. Dellaert \\ CentER for Economic Research and Economics Institute Tilburg \\ Tilburg University \\ PO Box 90153, 5000 LE Tilburg \\ The Netherlands \\ phone: +31134668224 \\ fax: +31134663066 \\ email: dellaert@kub.nl \\ Barbara E. Kahn \\ Department of Marketing \\ The Wharton School \\ University of Pennsylvania \\ Philadelphia, Pennsylvania 19104
}

\begin{abstract}
How consumers' waiting times affect their retrospective evaluations of Internet Web Sites is investigated in four computer-based experiments. Results show that waiting can but does not always negatively affect evaluations of Web Sites. Results also show that the potential negative effects of waiting can be neutralized by managing waiting experiences effectively. A conceptual framework and formal random utility model is introduced.
\end{abstract}

Keywords: Marketing, Consumer preference models, Waiting experiences, Internet marketing

JEL classification: $D 12, M 31$ 
The Internet is becoming increasingly important as a channel between marketers and consumers both for communicating information and for selling products. One of the big criticisms expressed by many consumers in using the Internet is that it takes a long time to download materials on some Web Sites. Due to congestion, delays are also experienced in simply accessing some Web Sites or in accessing some on-line services (e.g., AOL's famous problems when they changed their pricing strategy). It is possible that as the programs get more extensive and the World Wide Web gets more popular, delays and waiting will prevail even as the hardware gets more efficient. These fears have motivated some to nickname the WWW as the "World Wide Wait" rather than the World Wide Web.

In this paper, we investigate how negative waiting experiences can affect consumers' evaluations of material accessed over the Internet. We draw on research on the effects of waiting in conventional services (e.g., Dubé, Schmitt and Leclerc 1991, Hui, Dubé, and Chebat 1997, Hui and Tse 1996, Katz, Larson, and Larson 1991, Kumar, Kalwani and Dada 1997, Maister 1985,Taylor 1994, Zakay 1989) to predict how delay and more critically how managing the delay is likely to affect retrospective evaluation of Websites.

We introduce a conceptual framework and formal random utility model to capture the dynamics of consumer evaluations of waiting and Website experiences after waiting. Through four experiments, we show that waiting can negatively affect evaluations of Websites. However, we show that these negative effects of waiting on site evaluations can be neutralized if the waiting experiences are managed effectively. Our findings should be of interest to marketing managers wanting to learn how to manage unavoidable delays that consumers may experience when accessing information or services on the World Wide Web. 


\section{CONSUMERS' EVALUATIONS OF INTERNET WEBSITES}

\section{Sequence of Web-Events}

We consider consumers' experiences on the Internet as a set of sequential Web-events (e.g., waiting to download, viewing Web-page 1, viewing Web-page 2, etc.) each of which provide a certain utility. These events can be mentally grouped into episodes both in time and in relationship to a specific Internet Website (e.g., a session on the Website of manufacturer $X$ from 8 p.m. to 8.15 p.m. represents one Web-episode consisting of multiple Web-events). In formal

notation: let $E_{j i n}$ be the $j^{\text {th }}$ episode that consumer $i$ experiences on the Web site of supplier $n$, and let $e_{k j i n}$ be Web-event $k$ in episode $j .{ }^{1}$

For simplicity we will develop our model for a basic Website episode as consisting of two events: (1) the waiting experience and (2) the Website reading or interaction experience. Mathematical extension of the model to multiple events is straightforward, although practical observations may become complex.

\section{Carry-Over Effects}

Consumers' evaluations of one event within an episode may affect the evaluation of another event. For example, the evaluation of the waiting time to download the Web-page may affect the subsequent evaluation of that page. In this model we identify the separate components or events of the Website episode and allow for a separately identifiable carry-over effect between events.

\footnotetext{
${ }^{1}$ For notational simplicity we will omit the subscripts $i$ and $n$ and assume each variable and parameter to be individual and/or supplier specific where relevant.
} 
The motivation to introduce this additional carry-over effect is based on the realization that we know from other contexts that evaluations of goods or services consumed at one point in time are often influenced by the previous consumption experience (e.g., Kahn, Kalwani and Morrisson 1986, Menon and Kahn 1995, Tversky and Griffin 1991). For example, consumers may choose the courses in a meal so that one complements the other, they may visit several different sights on a touring holiday to experience a variety of atmospheres, or they may evaluate the quality of a movie by relating it to previous movies that they have seen.

\section{Distinguishing Consumers' Utilities in Evaluating Websites}

We distinguish among four different notions of utility with regard to how consumers evaluate the Website experience. These notions and the terminology that we use, are based largely on the discussion in Kahneman, Wakker and Sarin (1997), but are adapted to describe Web-based sequences of consumer experiences.

Two of the four utility concepts are related to consumers' evaluations of Web-events $\left(e_{k j}\right)$, and the other two are related to evaluations Web-episodes $\left(E_{j}\right)$. With respect to events, consumers are assumed first to formulate expectations (or implicit predictions) for the experiences that they will have during each event (for example, an expectation of a waiting time that they will experience). This is called the predicted utility of an event $\left(U^{p}\right)$. Secondly, it assumed that consumers experience an other (possibly different) utility during each event. This is called the instant utility of an event $\left(U^{i}\right)$. Note that the discrepancy between predicted and instant utility is similar in nature to the traditional 'gap' between expectation and experience in the services marketing literature (e.g., Iacobucci et al. 1996).

With respect to episodes, two further utility notions are defined. First, it is assumed that consumers, when making a decision to access a certain Website or not, attach a utility to the total 
experience they expect to gain from that episode of visiting the Website. This is called the decision utility of the episode $\left(U^{d}\right)$. Secondly, after the episode, consumers are assumed to form one overall evaluation of the episode. This is called the remembered utility $\left(U^{r}\right)$ and is defined as a weighted function of the instant utility of the events in the episode (which can include the carryover effects between the events) and the discrepancies between predicted and instant utility of these events.

Figure 1 graphically represents this structure of four types of utility and their temporal relationships. It can be seen that the decision utility $U^{d}$ for accessing a specific Website for episode $E_{j+1}$ is based on the remembered utility $U^{r}$ of episode $E_{j}$. This remembered utility in turn is based on the instant utilities $U^{i}$ of the events $\left\{e_{j 0}, \ldots, e_{j K}\right\}$ in episode $E_{j}$ and the discrepancy of these utilities with the predicted utilities of the events $U^{p}$.

\section{-INSERT FIGURE 1 ABOUT HERE-}

The remembered utility of an episode is likely to be the main basis for the consumer decision utility in choosing to repeat an episode or not. Thus, remembered utility is of central concern to Website managers, and will be the construct that we focus on. Support for this focus is provided by Kahneman, Kirchner and Selten (1994, p. 27) who point out in a review article that discusses the different types of utilities that "Retrospective evaluations of the experienced utility of past episodes are undoubtedly the most important source of predictions of the hedonic quality of future outcomes." Although contextual factors may also affect consumers' predicted and decision utilities (for example, whether a Web-site is visited for buying or browsing), these latter 
factors are frequently outside the control of the Website manager and we will not consider them here.

Finally, we note that a key proposition of this research is that consumers can mentally separate their evaluations of episodes and events and may regard them differently retrospectively. In particular, we posit that whereas waiting will usually be evaluated negatively in the retrospective evaluation of an episode that is defined by the consumer to include the wait and the Website reading event, it may not have a significant effect on the retrospective evaluation of the Website reading event alone. Depending on this carryover effect the consumer's evaluation of the Web site episode may be affected more or less strongly by the waiting event (i.e., waiting may or may not spoil the consumer's retrospective evaluation of the Web site).

\section{THE ROLE OF WAITING IN REMEMBERED UTILITY OF THE WEBSITE EPISODE}

Based on the existing services literature on the effects of waiting, we predict that the following factors will affect consumers' evaluations of waiting time in an Internet experience:

1. How long the wait is;

2. Whether the consumer experiences uncertainty about the waiting time;

3. The kind of information that is provided about the wait;

4. Where the waiting occurs within the Internet episode; and

5. How long the wait is compared to the consumers' expectations.

These aspects of the waiting event may have carryover effects on instant utility of the Website reading event. If the wait is well-managed however, there may not be carryover effects on the 
Website reading event. We are specifically interested in how different aspects of the waiting experience and different wait-management strategies may affect the remembered utility of the Website reading event in isolation. These aspects are summarized graphically in Figure 2 and discussed in more detail below.

- INSERT FIGURE 2 ABOUT HERE-

\section{Duration of the Wait}

Although it may intuitively seem likely that longer waits will be perceived as more negative than shorter waits, there has been some empirical evidence to the contrary. Research evaluating hedonic experiences has found that the duration of the experience often has surprisingly little effect on retrospective evaluations (Kahneman, Kirchner and Selten 1994, Kahneman, Wakker and Sarin 1997). For example, Carmon and Kahneman (1993) found that a longer wait that was more pleasant at the end (e.g., rapid progress at the end) was more appreciated than a shorter, less pleasant wait. Hui and Zhou (1996) also found that the role of perceived waiting duration affected consumers' service evaluations to a much lesser extent than whether the wait was longer or shorted than expected. If the actual duration times are pointed out, however, people may take them into consideration in their evaluations (Varey and Kahneman 1992).

Based on these results, we hypothesize that if the duration of the wait is not salient to the consumer, longer waits may not be evaluated as significantly worse than shorter waits (within a reasonable amount of time). Thus the duration of the wait may not have a significant effect on the remembered utility of the Website reading event, although it is likely to have an effect on the remembered utility of the wait and reading event episode. 


\section{Uncertainty and Waiting Information}

Research in the services literature has shown that consumers have an aversive reaction to not knowing how long they will have to wait (Leclerc, Schmitt and Dubé 1995, Taylor 1994) and that this aversive reaction influences the evaluation of the service encounter. Specifically, Taylor (1994) shows that the process by which uncertainty influences overall service satisfaction is through affect. Her findings indicate that uncertainty about the waiting time does not influence consumers' service evaluations directly, but rather influences their affective response to the service, which in turn influences consumer service evaluations. Hui and Tse (1996) also find negative effects on consumer mood, when consumers had no information about the wait, and thus were uncertain about how long they would have to wait.

Based on these findings, we hypothesize that if a consumer is uncertain about how long they will have to wait before they can access the Website of interest there will be negative affect and this negative affect will affect the evaluation of the Website reading event. This negative effect on the Website reading event will result in a more negative retrospective evaluation. If on the other hand, the uncertainty is mitigated and the negative affect is reduced there may not be an effect on the instant utility of the Website event and thus not on the remembered utility.

\section{Waiting Information}

One way to reduce the uncertainty about the wait is to provide information. There are two basic kinds of information that we consider: duration information provided at the beginning of the wait and countdown information. Duration information would simply tell the consumer how long the wait would be. Countdown information is that which is provided at regular intervals and indicates how much of the Website has been downloaded at each point. Countdown information may or not also include an indication of how long the total waiting time is. 
Hui and Tse (1996) found that the absence or presence of waiting information influenced consumers' affective response to a service, which in turn affected their overall service evaluation. Specifically, they observed that the role of waiting information was minimal for waits that were shorter than expected; duration information was helpful for medium and long waits, and countdown information was particularly welcome for long waits (see also Taylor and Claxton 1994).

We therefore hypothesize that information about the wait will reduce the negative carryover effect of waiting on consumers' evaluation of the Website reading event, and thus can help alleviate any negative effect on the remembered utility of the event. When the waits are long, we hypothesize that countdown information will be more effective at mitigating any negative carryovers from the wait than duration information.

\section{Sequential Position of Wait}

Previous findings on where in the sequence of events the waiting takes place and it how affects service evaluations are difficult to generalize and seem to depend in part on the context of the service and the expectation of the consumers (e.g., Carmon, Shantikumar and Carmon 1995, Dubé, Schmitt and Leclerc 1991, Taylor and Claxton 1994). For example, waiting before a consumption experience was shown to lead to more negative affective reactions than waiting during or after the consumption experience (Dubé, Schmitt and Leclerc 1991, Maister 1985). On the other hand, Taylor and Claxton (1994) observed that air passengers' evaluations of on-board service was affected little by previously experienced pre-boarding delays.

In Internet applications, the general expectation is that large applications that involve graphics take some time to download (Sears, Jacko and Borello 1997), but once the application has been downloaded there should be no further delays. Given this expectation, consumers should 
be more accepting of a delay before the application begins than one that occurs within the Website because it will be easier for consumers to mentally segregate the wait from the Website experience. When the wait comes within the viewing of the Website, it is more likely to carryover into the instant utility of the Website and thus the remembered utility.

Therefore, we hypothesize, that the negative effect of waiting on consumers' remembered utility of the Website event should be lower if the waiting takes place before the Website is loaded than if the waiting takes place during the interaction with the Website.

\section{Expected vs. Experienced Waiting Time}

A key finding in the services literature is that satisfaction or evaluation of service performance is driven by expectations. If performance is better than expectations, satisfaction is high and if performance is worse the expectations satisfaction is low (see Iacobucci et al. (1996) for a review.) Similarly Hui and Zhou (1996) found that the longer the waiting time relative to the expected waiting time, the more negative its effect on consumer affect and satisfaction.

Thus we hypothesize that if waiting times are longer than expected, there will be a discrepancy between predicted and instant utility in the waiting event that will negatively impact affect, which will lower the instant utility of the Website reading event and will result in more negative remembered utility.

\section{FORMAL MODEL}

We can formalize the above hypotheses and assumptions in a random utility framework (e.g., McFadden 1986). In the general case, we express the remembered utility of Web-episodes as the sum of structural remembered utility terms (to capture the waiting event and the Website reading event) and a random error component that captures unexplained variance in the utility 
(e.g., due to missing service features, unobserved consumer individual characteristics or context effects). We can also express the remembered utility of only the Website reading event, inclusive of carryover effects from waiting.

Let $\boldsymbol{V}_{W j}$ be a vector describing the remembered utility of waiting experience $W$ in episode $j$. Let $\boldsymbol{V}_{R j}$ be a vector describing the remembered utility of reading Web-page $R$, also in episode $j$. Let $V_{\Delta W}$ be the carry-over effect of the predicted-instant utility discrepancy in the waiting experience on the utility of reading the Web-page. Let $\boldsymbol{V}_{W S}$ be the moderating effects (through affect) of uncertainty, lack of information, and relative position of the wait on Web-page consumption utility after a wait. Finally, let $\varepsilon_{j}$ represents a random error component of the utility for episode $j$.

Thus the formal for model for consumers' remembered utility of the Website episode including both the waiting and reading events is:

$$
U_{j}=\boldsymbol{V}_{W j}+\boldsymbol{V}_{R j}+V_{\Delta W j}+\boldsymbol{V}_{W S}+\varepsilon_{j}
$$

Which can be detailed as follows:

$$
U_{j}=\beta_{W j} X_{W j}+\beta_{R j} X_{R j}+\beta_{\Delta W j} X_{\Delta W j}+\beta_{U n c . W j} X_{U n c . W j}+\beta_{I n f . W j} X_{I n f . W j}+\beta_{\text {Pos.Wj }} X_{\text {Pos.Wj }}+\varepsilon_{j}
$$

where, $\beta_{W j} X_{W j}$ is the remembered utility of waiting for the Web-page, $\beta_{R j} X_{R j}$ is the remembered utility of reading the Web-page, $\beta_{\Delta W_{j}} X_{\Delta W j}$ is the carry-over effect of the discrepancy in predicted and instant utility of the waiting experience on the Web-page utility, and $\beta_{U n c . W j} X_{U n c . W j}$, $\beta_{\text {Inf.Wj }} X_{\text {Inf.Wj }}$, and $\beta_{\text {Pos.Wj }} X_{\text {Pos.Wj }}$ are the carry-over effects (mediated by affect) of uncertainty, information, and relative position in the waiting experience on the consumer's Web-page utility.

For completeness, we note that although this study focuses on measuring remembered utility, the probability that a consumer $i$ accesses a Website $n$ can also be described. It is described as the probability that the decision utility of Website $n$ for episode $j$ is higher than the 
expected utility of the best competing other activity $A$ that the consumer can undertake in the same period of time. If it is assumed that the remembered utility of episode $E_{j-1}$ is related by a monotonic transformation function $g$ to the consumer's decision utility for episode $E_{j}$, the ordinal properties of the consumer's utilities are identical for remembered and decision utilities. Thus, the probability of selecting Website $n$ for Web-episode $E_{j}$ is:

$$
\mathrm{P}\left(n_{E j}\right)=\mathrm{P}\left\{U_{E j}^{d}>U_{A}^{d}\right\}=\mathrm{P}\left\{\mathrm{g}\left(U_{E j-1}^{r}\right)>U^{d}{ }_{A}\right\}
$$

If $U_{A}^{d}$ is set to an arbitrary reference level of zero, $g\left(U_{E j}^{r}\right)$ can be estimated relative to this level. For example, if $\varepsilon_{j}$ and $\varepsilon_{A}$ take on independently and identically distributed Gumbel distributions this generates the well-known simple multinomial logit model (e.g., Ben-Akiva and Lerman 1985).

\section{EXPERIMENTS}

Four experiments were conducted to test the proposed model and conceptual framework. In the experiments, subjects were asked to evaluate concepts for a new Internet-magazine Website. The Website included several features such as cartoons, celebrity photographs, movie reviews and personal columns. These features could be accessed at the subjects' discretion by clicking on hotlinks buttons.

In all of the experiments, subjects were seated behind computers and told to follow the instructions appearing on the screen. Subjects were told that they would be evaluating some features for a new Internet-magazine Website. They were also told that it could take time for the magazine to be downloaded to their computers, and that the potential delays could be of varying lengths. In each of the experiments the amount of time that the subjects had to wait was a manipulated factor. In addition, in some of the experiments the amount of information provided 
about the wait was also manipulated. After the waiting period, subjects were then shown the magazine and allowed to search through it as they pleased. Finally, subjects were asked to give their retrospective evaluation of the total experience (i.e., the combined wait and Internetmagazine) and then of just the Internet-magazine alone.

\section{Experiment 1}

Subjects were business students at a major university in the Asia-Pacific region and a total of 97 students participated. They were randomly assigned to one of three conditions: (i) whether they had to wait 30 seconds, (ii) 240 seconds, or (iii) did not have to wait at all to view the Internet magazine. All were shown identical magazine Web pages after this wait. All subjects were fully informed about their waiting times: both duration and countdown information was provided and the waiting always preceded the interaction with magazine Web pages. Subjects were asked to evaluate retrospectively both: (i) the combined waiting and magazine reading experience and (ii) the magazine reading experience in isolation. These evaluations (consumers' latent utilities) were recorded using 10 point response scales with categories ranging from evaluations of 'very poor' to 'very good'.

Based on the previous null results on duration effects, we predicted that waiting versus no waiting would have a negative effect on the evaluation of the total episode (both wait and reading events), but that the length of the wait would not matter. In particular though, Experiment 1 was designed to test our basic proposition that consumers can separate waiting time from time spent engaged in interaction with the Website in retrospective evaluations. Thus we predicted that although whether subjects waited or not would affect the evaluation of the total Website episode (i.e., the waiting event and the reading event) it would not affect the evaluation of the reading event alone because full information was provided and there was no uncertainty about the wait. 
Our findings support the proposition that consumers can mentally separate waiting and Website reading experiences in their retrospective evaluations. Although there was a clear negative effect of waiting time on subjects' retrospective evaluations of the joint waiting and Website reading events, their evaluations of the Internet magazine only did not differ significantly between waiting conditions. We also found that whereas wait versus no wait negatively affected the joint evaluation of waiting and reading the magazine, there was no significant difference between the longer and shorter waiting periods (although directionally the longer wait was perceived to be more negative.) These results are summarized in Table $1 .^{2}$

\section{-INTRODUCE TABLE 1 ABOUT HERE-}

\section{Experiments 2,3 and 4: Method}

Experiments 2, 3 and 4 focused on how different kinds of information about waiting time could affect subjects' retrospective evaluations of Internet Websites. There were three different sets of Internet-magazine features, one associated with each experiment. Approximately 200 business students at two major universities, one in the Asia-Pacific region and one in the USA participated. All subjects participated in all three experiments and the order of the experiments was counter-balanced across subjects. ${ }^{3}$

\footnotetext{
${ }^{2}$ Two different groups of subjects were used in this experiment. The factors in the analysis are therefore waiting condition ( 2 degrees of freedom), groups ( 1 degree of freedom), and wait*group ( 2 degrees of freedom). The group effect and the interaction were not significant so they are not reported.

${ }^{3}$ The sample size for all three experiments is not exactly the same because some subjects did not finish all three experiments, or their data were not accurately recorded.
} 
Each experiment had three between-subjects waiting conditions: (i) no wait, (ii) a fullyinformed waiting condition (both duration and countdown information provided), and (iii) a waiting condition with uncertainty and/or missing information about the waiting times. As in Experiment 1, subjects were asked to rate their retrospective evaluations of these Internet magazines with and without waiting.

Subjects were assigned to the waiting conditions in each of three experiments via a Latin Square design such that each subject participated in all three different waiting conditions, one in each experiment. This design allowed us to analyze each experiment separately using a betweensubjects ANOVA analysis to measure the effects of different waiting conditions. The design also allowed us to analyze the effect of individual-difference factors on response to waiting conditions by aggregating the data across all three experiments.

In these experiments, we manipulated several characteristics of the waiting experience. They were: length of wait, level of uncertainty of the wait, whether duration information was provided, whether continuous countdown information was provided, and the relative positioning of the wait with regard to the Internet magazine. The exact design of each experiment will be described in the next sections. Generally, though, these variables were defined and manipulated as follows:

1. Length of wait was either 0 minutes or 4 minutes.

2. Uncertainty of the wait was manipulated in the introductory text of the experiment. Subjects were either told that there was a possibility that they would have to wait with some uncertainty about the length of the wait, or that they would certainly have to wait for 4 minutes. 
3. Type of information offered was manipulated in two variables that both varied over two levels. Subjects were given countdown information at regular intervals that indicated the progress that had been made in downloading the program, and/or were told initially the duration of how long they would have to wait in seconds, or they did not receive any waiting information at all.

4. Sequential position of waiting vis-à-vis the Internet magazine was manipulated by changing where the waiting occurred. Waits occurred either before subjects viewed the Internet magazine, or in the middle of their interaction with the magazine.

At the end of the last experiment, we also collected some information to test for the mediating effects of affect and expectations. Both mediating variables were measured after subjects had viewed their last magazine and only in reference to this last magazine. So every subject provided ratings, but each magazine and its waiting time was only evaluated by $1 / 3$ of the subjects. Expectation-experience discrepancies were measured on a 100 point rating scale with subjects rating the waiting time as 'much longer' to 'much shorter' than expected. Consumer affect with regard to the wait and to the magazine was measured using the pleasure and arousal dimensions of the Mehrabian and Russell (1974) PAD emotions scale.

Across all three experiments, an ANOVA analysis was conducted to compare subjects' responses between magazines and locations (Asia-Pacific vs. USA). In general, subjects were positive about the magazine concepts. No significant interactions existed between the effects for magazines, locations, waiting condition, carry-over variables manipulated in the experiment (i.e. uncertainty, information and sequential position), and subjects expectation-experience discrepancies. However, main effects for location $(F(2,558)=18.82, p=0.001)$ and magazine $(F(1,554)=5.54, p=0.02)$ were significant. Subjects in the U.S. were slightly less positive about 
the magazine concepts than subjects in the Asia-Pacific region. In addition, the magazine used in Experiment 3 was evaluated less positively than the magazines in the other two experiments. As no interactions existed between location and the other variables, we aggregated across locations in our further analysis.

\section{Experiment 2}

Whereas in Experiment 1, all subjects were fully informed about the waiting situation, the goal of Experiment 2 was to see how uncertainty about the wait would affect the evaluation of the Internet magazine. 206 subjects participated in the experiment and were randomly assigned to one of three conditions: (i) A no waiting condition, (ii) A fully informed waiting condition (i.e. no uncertainty, both countdown and duration information provided ${ }^{4}$, and (iii) An uncertain waiting condition in which both the probability of waiting and the expected duration of the wait were uncertain, but in which countdown information during the wait was provided.

We hypothesized that the uncertainty in the waiting would have a negative carry-over effect on consumers' instant utility of the Internet magazine, because the uncertainty would create negative affect. The fully informed waiting condition was expected to mitigate the negative affect of waiting, and thus not carryover to the instant utility of the Internet magazine. Thus retrospective evaluations of the Internet magazine alone would be lower in the uncertain condition than they would be in the no wait and fully informed conditions. Finding no significant differences in the evaluation of the Internet magazine given no waiting or a fully informed waiting condition would replicate the effects of Experiment 1.

\footnotetext{
4 This condition is the same as the long-wait condition in Experiment 1.
} 
Table 2 summarizes the results of the experiment. ${ }^{5}$ Replicating Experiment 1, we found no significant differences in the retrospective evaluation of the magazine in the fully informed condition as compared to the no waiting condition, even though the waiting effect was significant in the evaluation of the combined waiting and magazine events. Furthermore, there was a directional negative effect of uncertainty, both in the combined waiting and magazine evaluation, and in the evaluation of the magazine alone, but contrary to our expectations, this effect was not significant.

We also computed the time spent viewing the different magazines in the different wait conditions to see if waiting affected the amount of time subjects took to view the magazine. We found no significant difference among the conditions $(\mathrm{F}(2,200)=0.65, \mathrm{p}=.53)$. Subjects who did not wait at all spent an average of 102.49 seconds viewing the magazine, while subjects in the "fully informed wait" condition spent an average of 101.43 seconds and subjects in the "uncertain wait" condition spent an average of 92.98 seconds.

\section{- INSERT TABLE 2 ABOUT HERE-}

\section{Experiment 3}

Experiment 3 again looks at the effects of waiting information, and also investigates how the position of the wait affects evaluation of the Internet magazine. This was a $3 \times 2$ cell design including three waiting conditions: (i) no wait, (ii) fully informed wait (i.e. both countdown and

\footnotetext{
${ }^{5}$ In this analysis we also included an effect of country ( 1 degree of freedom) and wait*country ( 2 degrees of freedom) but these effects were not significant so they are not reported.
} 
duration information), and (iii) wait with no countdown and no duration information; ${ }^{6}$ and two positions for the waiting: (i) before viewing the magazine or (ii) in the middle of viewing of the magazine. 189 subjects were randomly assigned to the six cells.

We hypothesized that absence of waiting information, similar to the effect of uncertainty, would lead to lower retrospective evaluations of the magazine. We also hypothesized that in this Internet context, consumers would be more accepting of a delay before the application begins than one that occurs within the application.

Tables $3 \mathrm{a}$ and $3 \mathrm{~b}$ summarize our findings for this experiment. ${ }^{7}$ As Table $3 \mathrm{a}$ shows, we replicated the effects shown in the previous experiment. While a fully informed wait decreased the evaluation of the magazine with the wait, the retrospective evaluation for just the magazine alone was not significantly lower than that for the no wait condition. However, the retrospective evaluation of the magazine after the waiting condition with no information was significantly lower than for the other two conditions. Therefore, we conclude that if consumers are not provided information about the wait, that waits have a more lasting effect on the retrospective evaluation of the Website. If the wait is managed properly, these results show that there is no lasting effect on the retrospective evaluation of the Website.

\footnotetext{
${ }^{6}$ In the condition with no information, subjects were periodically informed that there was a short delay. This matched the periodic interruption that the countdown information provided. Thus the interruption was kept constant and the only aspect that systematically differed was whether or not information about how far along the subjects were was provided.

${ }^{7}$ We also included a country variable and all the associated interactions and included the wait*sequential position interaction. None of these effects was significant so they are not reported.
} 
Table $3 \mathrm{~b}$ shows the effect of the positioning of the wait. A wait before viewing the magazine is significantly better than a wait during the magazine both in evaluating the wait and the magazine and in the retrospective evaluation of the magazine. Thus the wait prior to the magazine was carried over less in the evaluation of the magazine.

\section{-INSERT TABLES 3A AND 3B ABOUT HERE-}

\section{Experiment 4}

The objective of Experiment 4 was to distinguish further between the effects of countdown and duration information on the carry-over effects of waiting on evaluation of Web pages. 187 subjects participated in this experiment. In Experiment 3 in the uncertain cell, both countdown information and duration information were absent so it was difficult to tell which was more effective at reducing the uncertainty. We hypothesized that because the waiting time here is long relative to the viewing time of the magazine, the countdown information would be more effective than the duration information at mitigating the negative effect of the waiting on the retrospective evaluation of the magazine.

To test this hypothesis subjects were randomly assigned to one of three conditions: (i) no wait, (ii) a fully informed wait, and (iii) a wait with countdown information only.

Results of the analysis are shown in Table $4 .{ }^{8}$ Both waiting conditions led to a significantly lower evaluation of the combined waiting and magazine episode than in the no waiting condition, but the absence of duration information did not make the evaluation

\footnotetext{
${ }^{8}$ We included a main effect of country (1 degree of freedom) and the country*wait interaction $(2$ degrees of freedom) in this analysis, but neither effect was significant so they are not reported.
} 
significantly worse. In addition the absence of duration information did not lead to significant reductions in retrospective evaluations of the magazine alone. Thus, countdown information had a stronger effect on reducing the negative carry-over effects of waiting on the instant evaluation of the magazine than did duration information.

\section{-INSERT TABLE 4 ABOUT HERE-}

\section{Random utility model}

Across experiments 2,3 and 4, we summarized the overall results in the random utility model, by estimating an ordered probit model on subjects' rating score of the magazine alone as the dependent variable and the various elements in the model as explanatory variables. An ordered probit model is appropriate if the dependent variable has ordinal data properties, but cannot be assumed to have interval or ratio data properties. This is typically the case for consumer utility ratings. The ordered probit model included the mediating variable, the difference in expected and experienced waiting time, that was introduced in our discussion of the formal utility model. This difference in expected and experienced waiting time was expected to affect the carry-over effect of waiting on the evaluation of the magazine. We hypothesized that the longer the experienced wait was relative to the expected wait, the more negative its effect on consumer affect and, consequently, the more negative its effect would be on the retrospective evaluation of the magazine.

Estimates of the utility model are presented in Table 5. This table can also be regarded as a summary of the previously observed effects in the ANOVA analysis combined with estimates for the impact of the expectation-experience discrepancies. Similar to the ANOVA findings, Table 5 shows a significant effect of wait versus no wait on the evaluation of the magazine, but 
this effect is compensated if the wait is managed through information. Further, the countdown information has a much stronger impact than the duration information. The position of the wait also has a significant effect on the evaluation of the magazine. Finally, as expected, waits that were shorter than expected led to higher evaluations of the service after waiting.

\section{-INSERT TABLE 5 ABOUT HERE-}

\section{The Role of Affect}

Throughout our discussion, affect was regarded as the vehicle by which the carry-over effect of waiting on the evaluation of the magazine takes place. The better consumer affect is managed in the waiting experience, the lower the expected carry-over effects of waiting on the evaluation of the magazine. The effect was analyzed across experiments 2, 3, and 4, and 196 subjects were used in this analysis. Table 6 shows the average arousal and pleasure ratings for the waits in the three conditions. ${ }^{9}$ Subjects in the no wait condition were asked to evaluate their affect prior to viewing the magazine. This served as a benchmark. As Table 6 shows, subjects in the fully managed wait were not significantly more agitated than the control subjects, but they did find the wait unpleasant. Subjects in the conditions where the wait was not fully managed, i.e., there was uncertainty about the wait, no countdown information was provided or no information was provided at all, were significantly more agitated and indicated more negative affect. These

\footnotetext{
${ }^{9}$ In this analysis we also included the main effect of experiment $(2,3$ or 4$)$ for which the affect information was being recorded ( 2 degrees of freedom), the wait*experiment interaction ( 4 degrees of freedom), the country variable (1 degree of freedom), the wait*country interaction ( 2 degrees of freedom), the country*experiment interaction (1 degree of freedom), and the wait*country*experiment interaction ( 4 degrees of freedom), but none of these effects were significant so they are not reported.
} 
results tentatively suggest that negative affect affects the evaluation of the magazine and the waiting episode. Further if the consumers are aroused or agitated, there may be carry-over to the retrospective evaluation of the magazine alone.

\section{-INSERT TABLE 6 ABOUT HERE-}

\section{DISCUSSION}

In this research we investigated the question: How does the waiting time needed to connect with certain Websites or to download some Web-pages affect subsequent evaluation of the Internet materials? To answer this question we developed a conceptual framework and formal model structure for describing how consumers derive utility from the Internet experience. Based

on the Kahneman, Wakker and Sarin (1997) framework, we identified four different concepts of utility that we think apply to the evaluation of Website materials. This model was tested on four computer-based experiments where subjects were asked to evaluate an Internet magazine, after having to wait for the magazine to appear on their computers.

One of the key contributions of our results is that we show that consumers can separate the waiting experience from their retrospective evaluation of the Internet site. Thus if the carryover effects of waiting are mitigated, waiting in and of itself may not be a significant barrier to consumers' enjoyment of the Internet materials. As waiting times seem to get longer and longer and Websites become more sophisticated and graphics-laden, and as more and more people logon to the Internet, these results should be of value to designers of Web pages.

Specifically, we show that waiting need not have a negative effect on consumers' retrospective evaluations of Internet Websites if the waiting time is well-managed. We conclude 
that if uncertainty about the waiting experience is reduced and countdown and/or duration time information is provided, consumers can retrospectively evaluate the Web material independently from their frustration with the waiting time. In addition, if waiting times are significantly shorter than expected, and if the waiting occurs in expected positions (e.g., before the Web material appears on the screen, not in the middle of the interaction), the negative carry-over effects of waiting experiences on subsequent Internet Websites are minimal.

Finally, we provide preliminary evidence of the process that drives our results. We find that in the case of waiting versus not waiting, consumers experience negative affect or feel unpleasantly about the waiting time, but this negative feeling does not carryover to the evaluation of the Web material. On the other hand, when there is uncertainty about the wait, and thus the consumer feels agitated or frustrated, then these arousal-type feelings can carryover into the evaluation of the Web materials.

Although we included subjects in two different countries in our study, further comparisons between culturally and socially based differences in waiting time response would be worthwhile. For example, variables such as income and education can be expected to affect consumers' value of time (e.g. Truong and Hensher 1985) and culturally driven perceptual differences may exist between consumers from different cultural backgrounds (e.g. Graham 1981).

Further research addressing the affective or cognitive process behind consumers' evaluations of and expectations for waiting times would also be valuable. Our study indicates that if managers can effectively communicate that waiting times will be reduced in future services, consumers generally will be able to account for this change in their decision calculus and their expected utility for the Internet service would not be biased by previous experienced 
waiting periods. Further research would help to indicate which communication strategies would be most effective for such a purpose. 


\section{REFERENCES}

Carmon, Ziv, J. George Shanthikumar, and Tali F. Carmon (1995), “A Psychological Perspective on Service Segmentation Models: The Significance of Accounting for Consumers' Perceptions of Waiting and Service," Management Science, 41, 1806-1815.

Carmon, Ziv and Daniel Kahneman (1993), “The Experienced Utility of Queuing: Experience Profiles and Retrospective Evaluations of Simulated Queues," Working Paper, Fuqua School, Duke University, 1993.

Dubé, Laurette, Bernd H. Schmitt and France Leclerc (1991), “Consumers' Affective Response to Delays at Different phases of a Service Delivery," Journal of Applied Social Psychology 21, 810-820.

Graham, Robert J. (1981), “The Role of Perception of Time in Consumer Research,” Journal of Consumer Research 7, 335-342.

Hui, Michael K., Laurette Dubé and Jean-Charles Chebat (1997), “The Impact of Music on Consumers' Reactions to Waiting for Services," Journal of Retailing 73, 87-104.

Hui, Michael K. and David K. Tse (1996), "What to Tell Consumers in Waits of Different Lengths: An Integrative Model of Service Evaluation," Journal of Marketing 60, 81-90. Hui, Michael K. and Lianxi Zhou (1996), “How Does Waiting Duration Information Influence Customers' Reactions to Waiting for Services?", Journal of Applied Social Psychology $26,1702-1717$.

Iacobucci, Dawn, Amy L. Ostrom, Bridgette M. Braig and Alexa Bezjian-Avery (1996), “A Canonical Model of Consumer Evaluations and Theoretical Bases of Expectations," Advances in Services Marketing and Management vol. 5, 1-44. 
Kahn, Barbara E., Manohar U. Kalwani and Donald G. Morrison (1986), "Measuring VarietySeeking and Reinforcement Behaviors Using Panel Data," Journal of Marketing Research 23, 384-390.

Kahneman, Daniel, Christian Kirchner and Reinhard Selten (1994), "New Challenges to the Rationality Assumption,” Journal of Institutional and Theoretical Economics 150, 18-36.

Kahneman, Daniel, Peter P. Wakker and Rakesh Sarin (1997), “Back to Bentham? Explorations of Experienced Utility", Quarterly Journal of Economics 112, 375-405.

Katz, Karen L., Blaire M. Larson, and Richard C. Larson (1991), "Prescription for the Waitingin-Line Blues: Entertain, Enlighten, and Engage.” Sloan Management Review 32 (Winter), 44-53.

Kumar, Piyush, Manohar U. Kalwani and Maqboll Dada (1997), “ The Impact of Waiting Time Guarantees on Customers’ Waiting Experiences”, Marketing Science 16, 295-314.

Leclerc, France, Bernd H. Schmitt and Laurette Dubé (1995), "Waiting Time and Decision Making: Is Time like Money?”, Journal of Consumer Research 22, 110-119.

Maister, David H. (1985), “The Psychology of Waiting Lines.” In John A. Czepiel, Mirchael R. Solomon, and Carol F. Surprenant (eds.) The Service Encounter: Managing Employee/Customer Interaction in Service Businesses. Lexington, MA: Lexington Books, 113-123.

McFadden, Daniel (1986), "The Choice Theory Approach to Market Research,” Marketing Science 5, 275-297.

Mehrabian, Albert and James Russel (1974), An Approach to Environmental Psychology, Cambridge, MA: the MIT Press. 
Menon, Satya and Barbara E. Kahn (1995), “The Impact of Context on Variety Seeking Product Choices", Journal of Consumer Research 22, 285-295.

Redelmeier, Donald A. and Daniel Kahneman (1997), "Patients' Memories of Painful Medical Treatments: Real-time and Retrospective Evaluations of Two Minimally Invasive Procedures," Pain 106, 3-8.

Sears, Andrew, Julie A. Jacko, and Micahel S. Borella (1997), “Internet Delay Effects: How Users Perceive Quality, Organization, and Ease of Use of Information," LateBreaking/Short Talks, Chi 97, 22-27 March, 353-354.

Taylor, Shirley (1994), "Waiting for Service: The Relationship Between Delays and Evaluations of Service," Journal of Marketing 58, 56-69.

Taylor, Shirley and John D. Claxton (1994), "Delays and the Dynamics of Service Evaluations," Journal of the Academy of Marketing Science 22, 254-264.

Truong, Truong P. and David A. Hensher (1985), "Measurement of Travel Time Values and Opportunity Cost from a Discrete-Choice Model," The Economic Journal 95, 438-451.

Tversky, Amos and Dale Griffin (1991), "Endowment and Contrast in Judgments of WellBeing," in: Richard J. Zeckhauser ed., Strategy and Choice, Cambridge, MA: MIT Press, 297-318.

Varey, Carol and Daniel Kahneman (1992), “Experiences Extended across Time: Evaluation of Moments and Episodes," Journal of Behavioral Decision Making 5, 169-185.

Zakay, Dan (1989), “An Integrated Model of Time Estimation.” In Iris Levin and Dan Zakay (eds.) Time and Human Cognition: A Life Span Perspective. Amsterdam: North Holland. 
Table 1 Experiment 1: Evaluations for different lengths of wait

\begin{tabular}{|c|c|c|c|c|}
\hline \multirow[b]{2}{*}{ WAITING TIME } & \multicolumn{2}{|c|}{$\begin{array}{c}\text { RETROSPECTIVE EVALUATION OF } \\
\text { COMBINED WAIT-INTERNET } \\
\text { MAGAZINE }\end{array}$} & \multicolumn{2}{|c|}{$\begin{array}{c}\text { RETROSPECTIVE EVALUATION OF } \\
\text { INTERNET MAGAZINE ONLY }\end{array}$} \\
\hline & EVALUATION & F-TEST & EVALUATION & F-TEST \\
\hline NO WAIT & $6.88^{A}$ & $F(2,91)=9.29$ & $7.08^{A}$ & $F(2,91)=0.07$ \\
\hline SHORT $(30 \mathrm{~S})$ & $5.81^{B}$ & $\mathrm{P}=0.00$ & $6.91^{A}$ & $\mathrm{P}=0.93$ \\
\hline $\operatorname{LONG}(240 \mathrm{~s})$ & $4.81^{B}$ & & $6.93^{A}$ & \\
\hline
\end{tabular}

${ }^{A, \boldsymbol{B}}$ Means within a column with different footnotes are significantly different, $\mathrm{p}<.01$. Means within a column with the same footnote are not significantly different, $\mathrm{p}>.10$. 
Table 2 Experiment 2: Effect of Uncertainty

\begin{tabular}{|c|c|c|c|c|}
\hline \multirow[b]{2}{*}{ WAIT } & \multicolumn{2}{|c|}{$\begin{array}{c}\text { RETROSPECTIVE EVALUATION OF } \\
\text { COMBINED WAIT-INTERNET } \\
\text { MAGAZINE }\end{array}$} & \multicolumn{2}{|c|}{$\begin{array}{l}\text { RETROSPECTIVE EVALUATION OF } \\
\text { INTERNET MAGAZINE ONLY }\end{array}$} \\
\hline & EVALUATION & F-TEST & EVALUATION & F-TEST \\
\hline NO WAIT & $6.56^{A}$ & $\mathrm{~F}(2,200)=11.56$ & $7.26^{A}$ & $\mathrm{~F}(2,200)=0.72$ \\
\hline $\begin{array}{l}\text { FULLY } \\
\text { INFORMED }\end{array}$ & $5.20^{B}$ & $\mathrm{P}=0.0001$ & $7.32^{A}$ & $\mathrm{P}=0.49$ \\
\hline UNCERTAIN & $4.89^{B}$ & & $6.90^{A}$ & \\
\hline
\end{tabular}

${ }^{A, B}$ Means within a column with different footnotes are significantly different, $\mathrm{p}<.01$. Means within a column with the same footnote are not significantly different, $\mathrm{p}>.10$. 


\section{Table 3a Experiment 3: Joint countdown and duration information effect}

\begin{tabular}{|c|c|c|c|c|}
\hline \multirow[b]{2}{*}{ WAIT } & \multicolumn{2}{|c|}{$\begin{array}{c}\text { RETROSPECTIVE EVALUATION OF } \\
\text { COMBINED WAIT-INTERNET } \\
\text { MAGAZINE }\end{array}$} & \multicolumn{2}{|c|}{$\begin{array}{l}\text { RETROSPECTIVE EVALUATION } \\
\text { OF INTERNET MAGAZINE ONLY }\end{array}$} \\
\hline & EVALUATION & F-TEST & EVALUATION & F-TEST \\
\hline NO WAIT & $5.94^{A}$ & $F(2,177)=25.15$ & $6.51^{A}$ & $F(2,177)=5.16$ \\
\hline $\begin{array}{l}\text { FULLY } \\
\text { INFORMED }\end{array}$ & $4.16^{B}$ & $\mathrm{P}=0.0001$ & $6.19^{A}$ & $\mathrm{P}=0.007$ \\
\hline $\begin{array}{l}\text { NO } \\
\text { INFORMATION }\end{array}$ & $3.46^{C}$ & & $5.42^{B}$ & \\
\hline
\end{tabular}

${ }^{A, B}, \boldsymbol{C}$ Means within a column with different footnotes are significantly different, $\mathrm{p}<.01$. Means within a column with the same footnote are not significantly different, $\mathrm{p}>.10$. 
Table $3 b$ Experiment 3: Effect of sequential position

\begin{tabular}{|c|c|c|c|c|}
\hline \multirow[b]{2}{*}{$\begin{array}{l}\text { POSITION OF } \\
\text { WAIT }\end{array}$} & \multicolumn{2}{|c|}{$\begin{array}{c}\text { RETROSPECTIVE EVALUATION OF } \\
\text { COMBINED WAIT-INTERNET } \\
\text { MAGAZINE }\end{array}$} & \multicolumn{2}{|c|}{$\begin{array}{l}\text { RETROSPECTIVE EVALUATION } \\
\text { OF INTERNET MAGAZINE ONLY }\end{array}$} \\
\hline & EVALUATION & F-TEST & EVALUATION & F-TEST \\
\hline BEFORE SERVICE & $4.90^{A}$ & $F(1,177)=8.25$ & $6.40^{A}$ & $F(2,177)=9.58$ \\
\hline DURING SERVICE & $4.20^{B}$ & $\mathrm{P}=0.005$ & $5.70^{B}$ & $\mathrm{P}=0.002$ \\
\hline
\end{tabular}

${ }^{A, B}$ Means within a column with different footnotes are significantly different, $\mathrm{p}<.01$. Means within a column with the same footnote are not significantly different, $\mathrm{p}>.10$. 
Table 4 Experiment 4: Duration information effect

\begin{tabular}{|c|c|c|c|c|}
\hline \multirow[b]{2}{*}{ WAIT } & \multicolumn{2}{|c|}{$\begin{array}{c}\text { RETROSPECTIVE EVALUATION OF } \\
\text { COMBINED W AIT-INTERNET } \\
\text { MAGAZINE }\end{array}$} & \multicolumn{2}{|c|}{$\begin{array}{l}\text { RETROSPECTIVE EVALUATION } \\
\text { OF INTERNET MAGAZINE ONLY }\end{array}$} \\
\hline & EVALUATION & F-TEST & EVALUATION & F-TEST \\
\hline NO WAIT & $6.73^{A}$ & $\mathrm{~F}(2,181)=15.52$ & $7.32^{A}$ & $\mathrm{~F}(2,181)=0.80$ \\
\hline FULLY INFORMED & $5.14^{B}$ & $\mathrm{P}=0.0001$ & $7.24^{A}$ & $\mathrm{P}=0.45$ \\
\hline $\begin{array}{l}\text { QUEUING INFO } \\
\text { ONLY }\end{array}$ & $5.02^{B}$ & & $6.94^{A}$ & \\
\hline
\end{tabular}

${ }^{A, \boldsymbol{B}}$ Means within a column with different footnotes are significantly different, $\mathrm{p}<.01$. Means within a column with the same footnote are not significantly different, $\mathrm{p}>.10$. 
Table 5 Utility model (Ordered Probit results): Experiments 2,3 and $4(N=198)$

\begin{tabular}{|c|c|c|}
\hline Variable & Estimate & p-level \\
\hline EXPERIMENT 3 DUMMY & -0.23 & .000 \\
\hline $\begin{array}{l}\text { EFFECT OF WAIT (VS. NO } \\
\text { WAIT) }\end{array}$ & -0.10 & .087 \\
\hline $\begin{array}{l}\text { EFFECT OF FULLY-INFORMED } \\
\text { WAIT (VS. NO WAIT) }\end{array}$ & 0.09 & .199 \\
\hline COUNTRY (ASIA-PACIFIC) & 0.04 & .317 \\
\hline COUNTDOWN INFORMATION & 0.30 & .010 \\
\hline DURATION INFORMATION & -0.07 & .477 \\
\hline $\begin{array}{l}\text { SEQUENTIAL POSITION } \\
\text { (DURING) }\end{array}$ & -0.08 & .061 \\
\hline$\triangle$ EXPECTATION-EXPERIENCE & 2.87 & .000 \\
\hline
\end{tabular}


Table 6 The role of affect: experiments 2,3 and 4

\begin{tabular}{|c|c|c|c|c|}
\hline \multirow[b]{2}{*}{ WAIT } & \multicolumn{2}{|c|}{ AROUSAL OF WAIT ${ }^{1}$} & \multicolumn{2}{|c|}{ PLEASURE OF WAIT $^{1}$} \\
\hline & EVALUATION & F-TEST & EVALUATION & F-Test \\
\hline NO WAIT & $57.89^{A}$ & $F(2,180)=7.23$ & $50.15^{A}$ & $F(2,180)=24.54$ \\
\hline FULLY INFORMED & $60.77^{A}$ & $\mathrm{P}=.001$ & $67.23^{B}$ & $\mathrm{P}=.0001$ \\
\hline $\begin{array}{l}\text { UNCERTAIN \& NO } \\
\text { INFORMATION \& } \\
\text { COUNTDOWN ONLY }\end{array}$ & $68.88^{B}$ & & $70.65^{B}$ & \\
\hline
\end{tabular}

${ }^{1}$ Higher numbers are more negative

${ }^{A, B}$ Means within a column with different footnotes are significantly different, $p<.01$. Means within a column with the same footnote are not significantly different, $\mathrm{p}>.10$. 
FIGURE 1 ACROSS-EPISODES UTILITY FRAMEWORK

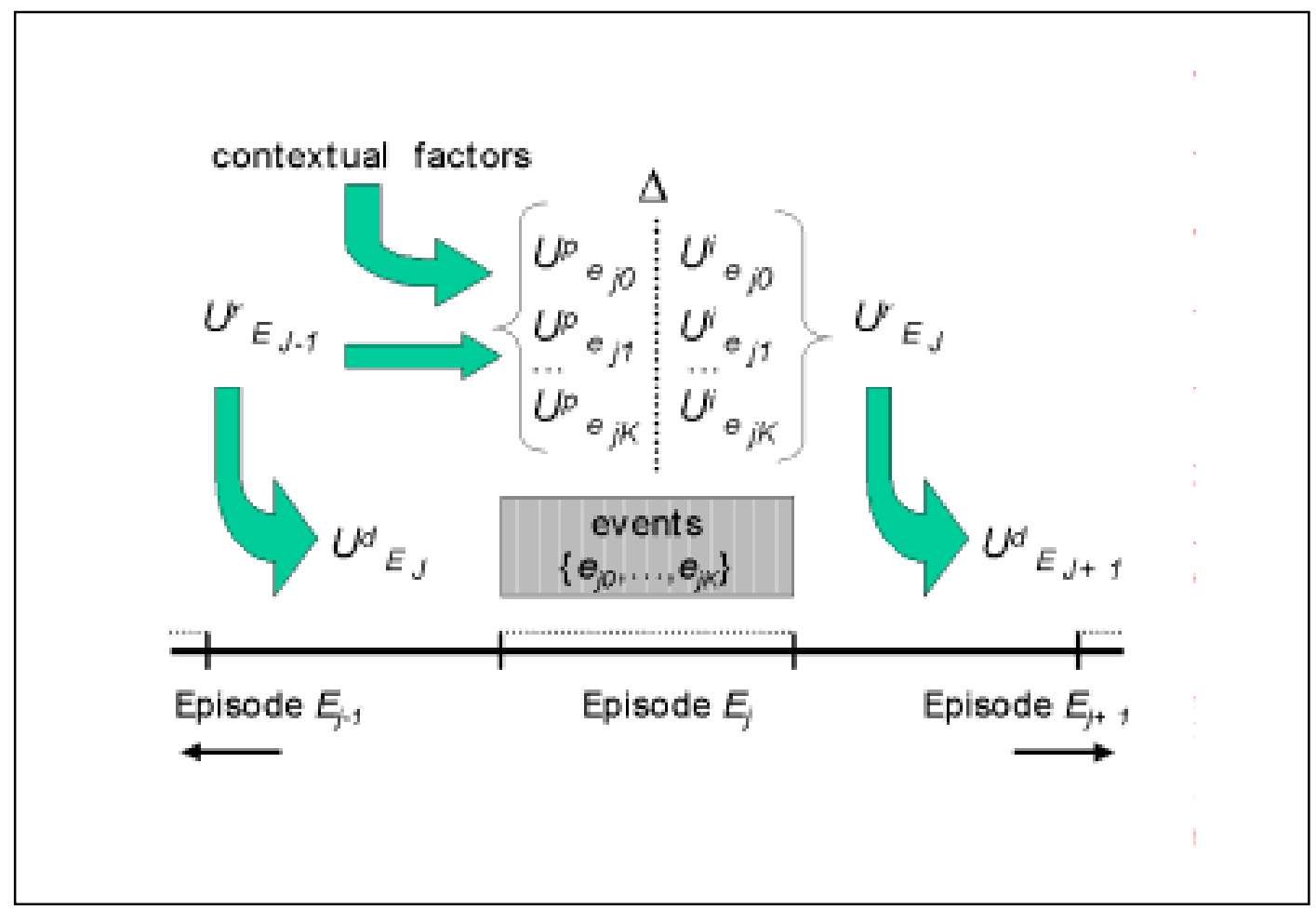


FIGURE 2 WITHIN-EPISODES UTILITY FRAMEWORK

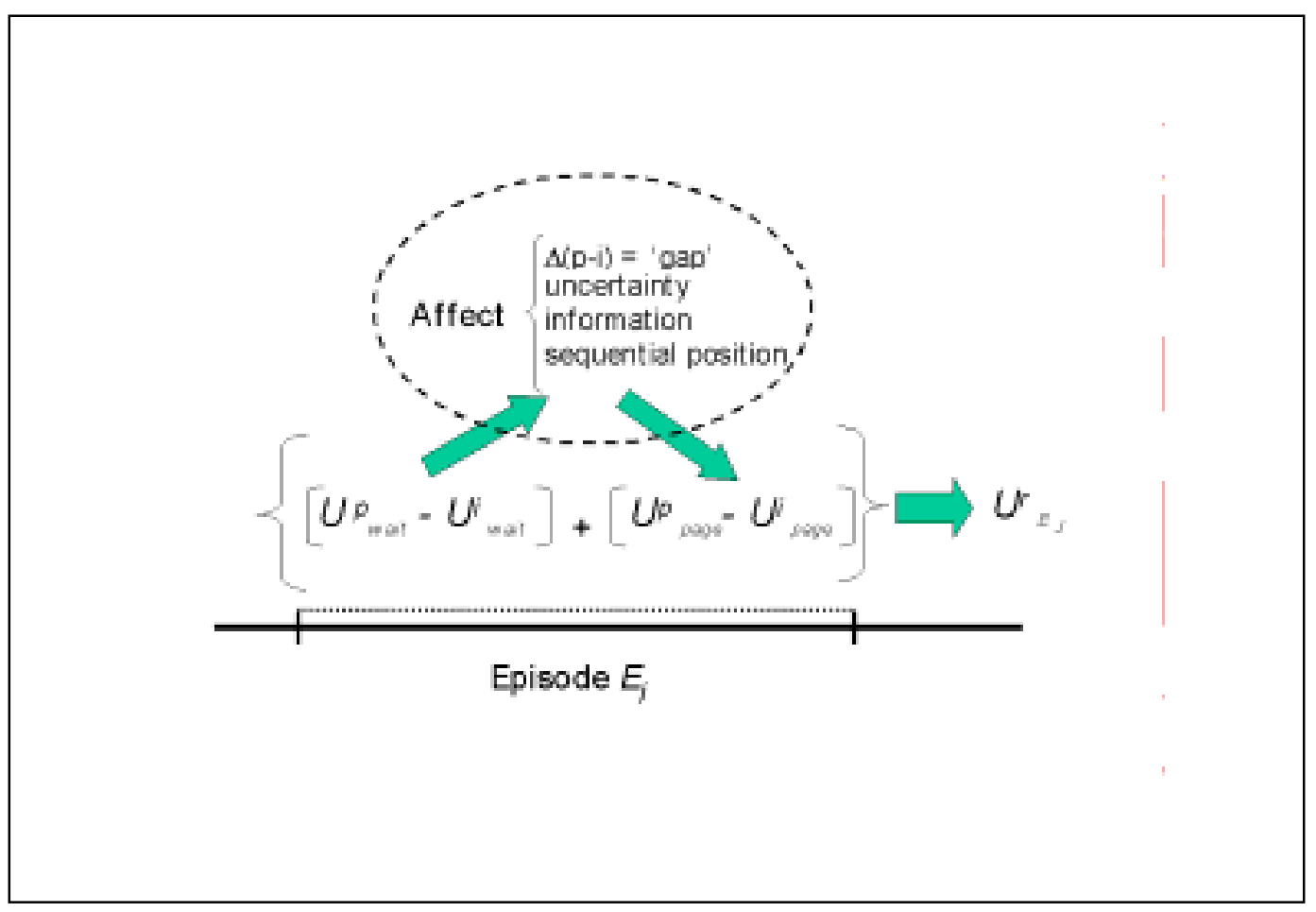

